\title{
Fatty acids in serum lipid fractions as indicators of fat intake in 5-year-old children in the STRIP project
}

\author{
By Hanna Lagström, Eero Jokinen, Ritva Seppänen, Pia Salo, \\ Jorma Viikari, Tapani Rönnemaa, Hans Helenius and Olli Simell \\ Received: August 24, 1998; Accepted: October 7, 1998
}

\begin{abstract}
The objective of the present study was to investigate the association between dietary fat composition and the proportion of fatty acids in serum lipid fractions as biomarkers of previous dietary fat quality in 5-year-old children. Using 4-consecutive-day food records, the food consumption of half $(\mathrm{n}=50)$ of a group of randomly selected children who are participating in a prospective randomized coronary risk factor intervention project (STRIP; $\mathrm{n}=1062$ at recruitment at 7 months of age) was estimated immediately prior to a blood sampling for analysis of fatty acids in serum lipid fractions, whereas in the other half of the group $(\mathrm{n}=52)$, food consumption was measured 5 to 15 days before the sampling. Nutrient intakes were analyzed using the MicroNutrica program. The fatty acid composition of serum triglycerides (TG), cholesterol esters (CE) and phospholipids (PL) was analyzed using gas chromatography.

When intake was recorded immediately prior to measurement of serum fatty acids, SAFA intake was significantly correlated to TG-SAFA, but did not correlate with CE-SAFA or PLSAFA. PUFA intake was significantly correlated to serum TG-PUFA and CE-PUFA. When intake had been recorded 5 to 15 days prior to measurement of serum fatty acids, SAFA intake was significantly correlated to TG-SAFA. Significant correlation was also obtained between dietary and serum PUFA in serum TG fraction. The correlations between MUFA intake and serum MUFA concentrations were always poor irrespective of when intake had been recorded.

In conclusion, serum TG-SAFAs reflect short-term SAFA intake and serum TG-PUFAS reflect short-term PUFA intake in 5-year-old children.
\end{abstract}

\section{Introduction}

Fatty acid compositions of adipose tissue, erythrocyte and platelet membranes and serum lipid fractions have been used to estimate previous fat intake and proportions of fat types consumed $(1,2)$. Dietary fat intake over a relatively long period is assumed to be reflected in adipose tissue fatty acids, whereas medium-term dietary intake is reflected by fatty acids in serum cholesterol esters (CE) and phospholipids (PL) (1). As biomarkers of immediately preceding intake of dietary fatty acids, serum CE fatty acids have been widely used (3-6), although fatty acids in serum triglycerides (TG) may reflect short-term intake even better $(2,7)$.

Accurate estimation of food consumption is difficult in children as dietary assessment methods have been construc-

Hanna Lagström ${ }^{1}$ MSc, Eero Jokinen ${ }^{2}$ MD, Ritva Seppänen ${ }^{3}$ DSc, Pia Salo ${ }^{1}$ MD, Jorma Viikari ${ }^{4}$ MD, Tapani Rönnemaa ${ }^{4}$ MD, Hans Helenius ${ }^{5}$ MSc, Olli Simell ${ }^{6}$ MD.

${ }^{1}$ Cardiorespiratory Research Unit and Departments of ${ }^{6}$ Pediatrics, ${ }^{4}$ Medicine, ${ }^{5}$ Department of Biostatistics, University of Turku, Turku, ${ }^{2}$ Hospital for Children and Adolescents, University of Helsinki, Helsinki, ${ }^{3}$ Research and Development Centre of the Social Insurance Institution, Turku, Finland.

Correspondence: Hanna Lagström, Cardiorespiratory Research Unit, University of Turku, Kiinamyllynkatu 10, FIN-20520 Turku, Finland. ted mainly for adult populations and may function inappropriately in young age groups. The fatty acid profile of several serum lipid fractions has been determined in healthy children (8-15), but only occasionally has the data also included information about fatty acid intake. Some data is available about the connection between type of fat ingested and the fatty acid composition of serum cholesterol esters and phospholipids in children $(13,15,16)$, but the link between shortterm dietary fat intake of children and the fatty acid composition of serum TGs has remained poorly characterized.

Basing our hypothesis on accumulated knowledge of the intermediary metabolism of lipids in serum lipid fractions, we speculated that the fatty acid composition of serum TGs might be the best reflector of immediately preceding dietary intake of fatty acids. To test this hypothesis, we evaluated the connections between fatty acid compositions of the three major serum lipid fractions, triglycerides, cholesterol esters and phospholipids, and the quality of recent and previous fat intake in a cohort of 5-year-old children.

\section{Subjects and methods}

The children in this study were participants in the STRIP project (Special Turku Coronary Risk Factor Intervention Project for Children), which is a prospective randomized trial aimed at decreasing the exposure of children to the known environmental risk factors of coronary heart disease. The trial, described in detail elsewhere $(17,18)$, included 1062 children in 1054 families, who were randomized to an intervention $(n=540)$ or a control group $(n=522)$ at the child's age of 6 months. Frequently repeated counseling of the intervention families aimed at reducing children's intake of saturated fat and cholesterol and correspondingly increásing the intake of monounsaturated and polyunsaturated fat. The control families received only general dietary information as currently delivered at Finnish wellbaby clinics.

The children were recruited for the STRIP trial between March 1990 and June 1992. This study was carried out between May 1994 and June 1995. One hundred and two 5-year-old children were randomly selected for this substudy among participants in the main project. They were divided into children whose 4-consecutive-day food consumption was recorded for the four days prior to the blood sampling $(n=50)$, and children whose 4 consecutive-day food recording was completed 5 to 15 days before the blood sampling $(n=52)$. Study groups comprising equal numbers of intervention 
Table 1. Fatty acid intake in the diet (4-day mean) and proportions of fatty acids in serum triglycerides, cholesterol esters and phospholipids in 5-year- old children. Values are means \pm SD.

\begin{tabular}{|c|c|c|c|c|c|c|c|c|c|c|c|c|}
\hline \multirow[b]{2}{*}{ Fatty acid } & \multicolumn{3}{|c|}{ Dietary intake as $\%$ total fat } & \multicolumn{3}{|c|}{ Serum triglycerides $\S$} & \multicolumn{3}{|c|}{ Serum cholesterol esters§ } & \multicolumn{3}{|c|}{ Serum phospholipids $§$} \\
\hline & $\begin{array}{c}\text { Group I } \\
\mathrm{n}=50\end{array}$ & $\begin{array}{c}\text { Group II } \\
\mathrm{n}=52\end{array}$ & $\mathrm{p}^{*}$ & $\begin{array}{c}\text { Group I } \\
n=50\end{array}$ & $\begin{array}{c}\text { Group II } \\
\mathrm{n}=52\end{array}$ & $\mathrm{p}$ & $\begin{array}{c}\text { Group I } \\
n=50\end{array}$ & $\begin{array}{c}\text { Group II } \\
\mathrm{n}=52\end{array}$ & $\mathrm{p}$ & $\begin{array}{c}\text { Group I } \\
n=49\end{array}$ & $\begin{array}{c}\text { Group II } \\
n=52\end{array}$ & $\mathrm{p}$ \\
\hline SAFA & $42.5 \pm 5.0$ & $40.5 \pm 4.7$ & 0.04 & $34.6 \pm 4.7$ & $35.6 \pm 5.3$ & 0.04 & $12.7 \pm 1.1$ & $13.5 \pm 1.2$ & 0.001 & $44.7 \pm 1.9$ & $45.3 \pm 2.5$ & 0.20 \\
\hline $\mathrm{C} 16: 0$ & $20.0 \pm 2.2$ & $19.2 \pm 2.1$ & 0.06 & $27.3 \pm 3.4$ & $27.9 \pm 3.7$ & 0.12 & $10.7 \pm 0.9$ & $11.3 \pm 1.0$ & 0.002 & $27.7 \pm 1.9$ & $28.0 \pm 1.8$ & 0.34 \\
\hline $\mathrm{C} 18: 0$ & $8.4 \pm 1.1$ & $8.2 \pm 1.2$ & 0.43 & $5.3 \pm 1.2$ & $5.6 \pm 1.4$ & 0.23 & $1.2 \pm 0.2$ & $1.4 \pm 0.3$ & 0.004 & $16.6 \pm 1.6$ & $16.9 \pm 1.3$ & 0.37 \\
\hline MUFA & $33.0 \pm 2.1$ & $33.9 \pm 2.2$ & 0.03 & $49.8 \pm 3.4$ & $49.6 \pm 3.3$ & 0.93 & $24.3 \pm 4.1$ & $24.9 \pm 4.0$ & 0.35 & $14.7 \pm 1.5$ & $15.0 \pm 1.5$ & 0.17 \\
\hline PUFA & $15.0 \pm 3.6$ & $15.8 \pm 2.8$ & 0.20 & $15.5 \pm 3.7$ & $14.7 \pm 4.7$ & 0.09 & $63.0 \pm 4.0$ & $61.6 \pm 4.4$ & 0.06 & $40.6 \pm 2.4$ & $39.7 \pm 3.3$ & 0.09 \\
\hline C18:2n-6 & $11.5 \pm 3.0$ & $11.7 \pm 2.7$ & 0.66 & $11.7 \pm 3.2$ & $11.0 \pm 3.8$ & 0.18 & $53.3 \pm 3.8$ & $52.7 \pm 3.9$ & 0.35 & $23.1 \pm 2.2$ & $23.0 \pm 2.4$ & 0.98 \\
\hline $\mathrm{C} 18: 3 n-3$ & $2.0 \pm 0.6$ & $2.1 \pm 0.8$ & 0.35 & $1.2 \pm 0.4$ & $1.1 \pm 0.6$ & 0.10 & $1.0 \pm 0.2$ & $0.9 \pm 0.2$ & 0.06 & $0.4 \pm 0.1$ & $0.3 \pm 0.1$ & 0.006 \\
\hline $\mathrm{P} / \mathrm{S}$ ratio & $0.37 \pm 0.13$ & $0.40 \pm 0.11$ & 0.16 & $0.47 \pm 0.17$ & $0.44 \pm 0.19$ & 0.07 & $4.98 \pm 0.57$ & $4.60 \pm 0.64$ & 0.001 & $0.91 \pm 0.08$ & $0.88 \pm 0.12$ & 0.15 \\
\hline
\end{tabular}

Group I: Food intake was recorded during the four days before the blood sampling; Group II: Food intake recording was finished 5 to 15 days before blood sampling; § Fatty acid proportions are expressed as $\%$ of all fatty acids in each serum lipid fraction; * Two-sample t-test

$(n=53)$ and control $(n=49)$ children and also boys $(\mathrm{n}=50)$ and girls $(\mathrm{n}=52)$.

The project has been approved by the Joint Ethics Committee of Turku University and the Turku University Central Hospital. Informed consent was obtained from all parents/guardians.

\section{Food consumption \\ and blood collection}

Food consumption was evaluated using food records kept by the parents or daycare personnel on four consecutive days, which had been chosen freely by the parents. Nutrient intakes were calculated using the Micro Nutrica ${ }^{\circledR}$ program developed at the Research Centre of the Social Insurance Institution, Turku, Finland.
This program uses the Food and Nutrient Data Base of the Social Insurance Institution and calculates 62 nutrients of the most commonly used foods and dishes in Finland and includes data on all foods commonly consumed by infants and children. The program is continuously updated.

After an overnight fast, a blood sample was drawn from the antecubital vein using minimal stasis. Cutaneous analgesia was attained with lidocaine and prilocaine creme (EMLA® ${ }^{\circledR}$, Astra; Södertälje, Sweden). After clotting of the venous blood sample at room temperature for 30 to 60 min and low-speed centrifugation $(3400 \mathrm{xg}$ for $12 \mathrm{~min}$ ), serum was separated and stored at $-25^{\circ} \mathrm{C}$ for a period of less than a month and then stored at $-80^{\circ} \mathrm{C}$ until analyzed.

\section{Analysis of fatty acids}

in serum lipid fractions

The fatty acid composition of serum triglycerides, cholesterol esters and phospholipids was analyzed using gas chromatography. Lipids were extracted from 0.5 $\mathrm{ml}$ serum aliquots with $6 \mathrm{ml}$ chloroformmethanol $(1: 1, \mathrm{v} / \mathrm{v})$. The extract was purified by the two phase system, and the lipid fractions were separated by thinlayer chromatography (Silica Gel 60 G, Merck, Darmstadt, Germany) using petroleum ether/ diethyl ether/acetic acid $(85: 15: 1, \mathrm{v} / \mathrm{v} / \mathrm{v})$ as the developing solvent. Fractions corresponding to triglycerides, cholesterol esters and phospholipids were located in UV light, scraped off and extracted five times with $4 \mathrm{ml}$ chloroform-

Table 2. Correlation coefficients between the proportions of fatty acids in the diet and in serum triglycerides, cholesterol esters or phospholipids. P-values for the correlation coefficients are in parenthesis.

\begin{tabular}{|c|c|c|c|c|c|c|c|c|c|}
\hline \multirow[b]{2}{*}{ Fatty acid } & \multicolumn{3}{|c|}{ Triglycerides } & \multicolumn{3}{|c|}{ Cholesterol esters } & \multicolumn{3}{|c|}{ Phospholipids } \\
\hline & $\begin{array}{c}\text { Group I } \\
\mathrm{n}=50\end{array}$ & $\begin{array}{c}\text { Group II } \\
\mathrm{n}=52\end{array}$ & $\mathrm{p}^{*}$ & $\begin{array}{c}\text { Group I } \\
\mathrm{n}=50\end{array}$ & $\begin{array}{c}\text { Group II } \\
\mathrm{n}=52\end{array}$ & $\mathrm{p}$ & $\begin{array}{c}\text { Group I } \\
\mathrm{n}=49\end{array}$ & $\begin{array}{c}\text { Group II } \\
\mathrm{n}=52\end{array}$ & $\mathrm{p}$ \\
\hline SAFA & $\begin{array}{c}0.48 \\
<0.001\end{array}$ & $\begin{array}{c}0.36 \\
(0.009)\end{array}$ & 0.48 & $\begin{array}{c}0.21 \\
(0.15)\end{array}$ & $\begin{array}{l}-0.008 \\
(0.69)\end{array}$ & 0.28 & $\begin{array}{c}0.10 \\
(0.49)\end{array}$ & $\begin{array}{l}-0.00 \\
(0.99)\end{array}$ & 0.62 \\
\hline C16:0 & $\begin{array}{c}0.36 \\
(0.01)\end{array}$ & $\begin{array}{c}0.23 \\
(0.10)\end{array}$ & 0.49 & $\begin{array}{c}0.13 \\
(0.38)\end{array}$ & $\begin{array}{l}-0.12 \\
(0.39)\end{array}$ & 0.22 & $\begin{array}{c}0.28 \\
(0.06)\end{array}$ & $\begin{array}{c}0.07 \\
(0.64)\end{array}$ & 0.29 \\
\hline $\mathrm{C} 18: 0$ & $\begin{array}{c}0.23 \\
(0.10)\end{array}$ & $\begin{array}{l}-0.02 \\
(0.91)\end{array}$ & 0.22 & $\begin{array}{c}0.05 \\
(0.71)\end{array}$ & $\begin{array}{l}-0.06 \\
(0.67)\end{array}$ & 0.59 & $\begin{array}{l}-0.27 \\
(0.06)\end{array}$ & $\begin{array}{l}-0.02 \\
(0.89)\end{array}$ & 0.21 \\
\hline MUFA & $\begin{array}{l}-0.29 \\
(0.04)\end{array}$ & $\begin{array}{c}0.08 \\
(0.55)\end{array}$ & 0.07 & $\begin{array}{l}-0.16 \\
(0.25)\end{array}$ & $\begin{array}{l}-0.06 \\
(0.68)\end{array}$ & 0.62 & $\begin{array}{c}-0.27 \\
(0.07)\end{array}$ & $\begin{array}{l}-0.04 \\
(0.76)\end{array}$ & 0.25 \\
\hline PUFA & $\begin{array}{c}0.69 \\
(<0.001)\end{array}$ & $\begin{array}{c}0.27 \\
(0.05)\end{array}$ & 0.01 & 0.35 & 0.06 & 0.14 & 0.34 & 0.03 & 0.12 \\
\hline $\mathrm{C} 18: 2 n-6$ & $\begin{array}{c}0.69 \\
(<0.001)\end{array}$ & $\begin{array}{c}0.27 \\
(0.05)\end{array}$ & 0.01 & $\begin{array}{c}0.30 \\
(0.03)\end{array}$ & $\begin{array}{c}0.11 \\
(0.44)\end{array}$ & 0.33 & $\begin{array}{c}0.11 \\
(0.43)\end{array}$ & $\begin{array}{l}-0.15 \\
(0.29)\end{array}$ & 0.21 \\
\hline $\mathrm{C} 18: 3 n-3$ & $\begin{array}{c}0.30 \\
(0.003)\end{array}$ & $\begin{array}{c}0.13 \\
(0.34)\end{array}$ & 0.38 & $\begin{array}{l}-0.13 \\
(0.36)\end{array}$ & $\begin{array}{l}-0.11 \\
(0.42)\end{array}$ & 0.92 & $\begin{array}{c}0.09 \\
(0.55)\end{array}$ & $\begin{array}{l}-0.17 \\
(0.23)\end{array}$ & 0.20 \\
\hline $\mathrm{P} / \mathrm{S}$ ratio & $\begin{array}{c}0.74 \\
(<0.001)\end{array}$ & $\begin{array}{c}0.26 \\
(0.07)\end{array}$ & 0.001 & $\begin{array}{c}0.43 \\
(0.002)\end{array}$ & $\begin{array}{l}-0.01 \\
(0.96)\end{array}$ & 0.02 & $\begin{array}{c}0.27 \\
(0.06)\end{array}$ & $\begin{array}{l}-0.02 \\
(0.91)\end{array}$ & 0.15 \\
\hline
\end{tabular}

Group I: Food intake was recorded during the four days before the blood sampling; Group II: Food intake recording was finished 5 to 15 days before blood sampling; * p for differences in correlation coefficients between Group I and Group II 
methanol $(2: 1, v / v)$. The fractions were dried in $\mathrm{N}_{2}$ stream and saponified with 0.5 $\mathrm{N} \mathrm{NaOH}$ in methanol at $100^{\circ} \mathrm{C}$ for $90 \mathrm{~min}$. The fatty acids were esterified with $20 \%$ $\mathrm{BF}_{3}$ in methanol at $85^{\circ} \mathrm{C}$ for $5 \mathrm{~min}$. After addition of $0.5 \mathrm{ml}$ of water saturated with $\mathrm{NaCl}$, the methyl esters were extracted three times with $1 \mathrm{ml}$ of $\mathrm{n}$-hexane and analyzed using a Varian 3700 gas chromatograph (capillary column, length $30 \mathrm{~m}$, diameter $0.25 \mathrm{~mm}$, filled with Durabond DB-225, thickness $1.15 \mu \mathrm{m})$. The temperature was programmed from $140^{\circ} \mathrm{C}$ to $220^{\circ} \mathrm{C}$. Fatty acids from $14: 0$ to $22: 6$ were quantified with a flame-ionization detector and a Spectra-Physics 4270 integrator. The amounts of the individual fatty acids (C14:0 to C22:6) are expressed as percentages of the total area of all fatty acids peak detected.

\section{Statistical methods}

The results are expressed as means and standard deviations (SD). The two sample t-test was used to analyze differences in food records between the groups. Analysis of covariance with food record values as covariate were used to test the differences in serum fatty acid proportions. Associations between numerical measurements were evaluated using Pearson's correlation coefficient. The test of equality of two correlations was perfomed using normal distribution after Fisher's Z-transformation. Statistical computing was performed using the SAS release 6.08 program package (SAS Institute, Cary, NC). Differences were considered significant at $\mathrm{P}<0.05$.

\section{Results}

\section{Fatty acids in children's diet and in serum lipid fractions}

The fatty acid compositions of the diets of children whose food consumption was recorded for the four days prior to blood sampling and that of children whose fourday food consumption was recorded 5 to 15 days prior to blood sampling resembled each other closely (Table 1). In serum triglycerides, SAFAs, MUFAs and PUFAs comprised $\approx 35 \%, \approx 50 \%$ and $\approx 15 \%$ of the fatty acids, respectively, in both groups of children. In serum cholesterol esters, SAFAs, MUFAs and PUFAs represented $\approx 13 \%, \approx 24 \%$ and $\approx 62 \%$ of all fatty acids, respectively, in children whose food consumption was recorded just before the blood sampling as well as in children whose food consumption was recorded 5 to 15 days prior to the blood sampling. In serum phospholipids, SAFAs, MUFAs and PUFAs comprised $\approx 45 \%, \approx 15 \%$ and $\approx 40 \%$ of all fatty acids, respectively, in both groups (Table 1). There were no differences in dietary fatty acid intake or serum fatty acid composition between girls and boys (data not shown).

\section{Dietary fat - fatty acid com- position of serum lipid fractions} In these calculations dietary fatty acid proportion was expressed as percentages of total fat intake and due to the glycerol component, the sum of SAFAs, MUFAs and PUFAs is below $100 \%$. On the other hand, fatty acid composition of serum lipid fractions was expressed as percentages of all fatty acids in each fraction. Thus, direct comparison of exact figures representing fatty acid intake and fatty acids in serum lipid fractions is not possible.

The proportions of SAFAs in serum triglycerides, cholesterol esters and phospholipids were slightly lower, markedly lower and almost similar to the respective proportions in the diet. The proportion of MUFAs in serum triglycerides was considerably higher than that in the diet, whereas the proportions of MUFA in serum cholesterol esters and phospholipids were lower than those in the diet (Table 1).

The proportion of PUFAs in serum triglycerides was very close to that of the diet measured just before the recording of food intake or earlier (Table 1). The proportion of PUFAs was 4 times higher in serum cholesterol esters than in the diet, PUFAs representing over $60 \%$ of all fatty acids in this lipid fraction in both groups of children (Table 1). The proportion of PUFAs in serum phospholipids was almost 3 times higher than their share in the diet.

\section{Serum lipid fractions and dietary intake of fatty acids} When dietary data were collected just before blood sampling, dietary intake of SAFAs correlated rather well with serum triglyceride SAFA (Figure 1) and moderately well with palmitic acid (Table 2). Dietary intake of PUFAs and serum triglyceride PUFAs correlated well, as did serum triglyceride linoleic acid and the P/S ratio when the dietary data were collected just before blood sampling. In the group of children whose food consumption was recorded 5 to 15 days prior to the blood sampling only the proportion of SAFAs correlated moderately well, while that of PUFAs and linoleic acid correlated weakly in serum triglycerides with the same dietary fatty acids. The proportion of MUFAs in serum triglycerides did not reflect the intake of MUFAs at all in either group (Figure 1). The differences in the correlations between the two groups of children with respect to triglycerides were significant for PUFA $(\mathrm{p}=0.01)$, linoleic acid $(\mathrm{p}=0.01)$ and the $\mathrm{P} / \mathrm{S}$ ratio $(\mathrm{p}=0.001)$ (Table 2).

When dietary data were collected just before blood sampling, the correlations between the dietary intake of PUFAs and the PUFA content of serum cholesterol esters or phospholipids were markedly poorer than those between dietary PUFA and PUFA in serum triglycerides. Both dietary intakes of PUFA and linoleic acid and the $\mathrm{P} / \mathrm{S}$ ratio of the diet correlated moderately well with the respective values in the serum cholesterol esters when food consumption was recorded immediately prior to the blood sampling (Table 2). In these children, the content of PUFAs in serum phospholipids also correlated reasonably well $(r=0.43)$ with the respective dietary fatty acids (Table 2 ). The proportion of fatty acids in serum cholesterol esters or serum phospholipids did not reflect the fatty acid composition of diet at all when the dietary data were collected 5 to 15 days before the blood sampling (Table 2).

The differences in the correlations between triglycerides and cholesterol esters were significant with respect to PUFA ( $p=0.02)$, linoleic acid $(p=0.02), \alpha-$ linolenic acid $(\mathrm{p}=0.04)$ and with respect to the $\mathrm{P} / \mathrm{S}$ ratio $(\mathrm{p}=0.02)$ in the group where the dietary data were collected just before blood sampling. Also in this group of children, the correlations were stronger in triglycerides than in phospholipids: the differences were significant with respect to SAFA $(\mathrm{p}=0.04)$, PUFA $(\mathrm{p}=0.02)$, linoleic acid $(\mathrm{p}<0.001)$ and $\mathrm{P} / \mathrm{S}$ ratio $(p=0.002)$. When food consumption was recorded 5 to 15 days before the blood sampling, no differences in the level of correlation were seen, either between triglycerides and cholesterol esters or between triglycerides and phospholipids.

The intake or serum fatty acid proportions in a few subjects differed from the corresponding mean values by more than 3 SD (Figures 1-3). All analyses were repeated without such outliers, but the results did not change essentially.

\section{Discussion}

In this study, saturated and polyunsaturated fatty acids in serum triglycerides correlated statistically significantly with the quality of fat in the diet of the 5-yearold children. The relatively fast turnover of fatty acids in serum triglycerides $(1,19)$ matched our results well. Previously, cholesterol ester fatty acids have been widely used as a measure of the short-term supply of dietary fatty acids (20), whereas fatty acids in serum phospholipids are believed to reflect poorly the immediately 
preceding dietary intake. On the other hand, phospholipid fatty acids may reflect more closely endogenously produced fatty acids as a result of intermediary fatty acid metabolism (7).

When the dietary intake data were collected by 4-day food records kept on the days immediately prior to the blood sampling, dietary PUFA correlated best with serum triglyceride PUFA and less well with cholesterol ester PUFA and phospholipid PUFA. The correlation between SAFA intake and SAFA in serum triglycerides in these samples was also statistically significant. Compared with the present study, almost similar correlations for all lipid fractions and diet have been reported in previous studies in adults $(5,21)$ and in Finnish children and young adults between dietary and cholesterol ester PUFAs (12) and between dietary and phospholipid PUFAs (16). On the other hand, dietary MUFA intake correlated inversely with MUFA in all three serum lipid fractions in previous studies $(12,15)$ as well as in our study.

The best biomarkers, which rapidly show changes in quality of fat intake, are probably the fatty acids that are not synthesized endogenously typically essential n-3 and n- 6 polyunsaturated and trans fatty acids (2). The serum fatty acid composition of serum lipid fractions depends not only on the diet but also on digestion, absorption, de novo synthesis, usage and catabolism, excretion and transfer to other body pools of the individual fatty acids (22). The metabolism of fatty acids by chain elongation, desaturation and retroconversion is regulated partly by a complex feedback network, where increased availability of one fatty acid may inhibit or induce elongation or desaturation of others. In this study, the proportion of MUFAs in serum triglycerides considerably exceeded that in the diet, probably because the first step in the desaturation of SAFAs produces MUFAs of the $n-9$ and $n-7$ series $(23,24)$. MUFA production via SAFA desaturation varies markedly, and this may explain why dietary intake so poorly predicts serum triglyceride MUFA.

The affinities of the fatty acid desaturation enzymes for individual fatty acids also vary markedly (23-25), and fatty acids of the three main series of unsaturated fatty acids (n-3, n-6 and n-9) compete for the same elongation and desaturation enzymes. A consequence of such complex metabolic interaction is that an increase in the intake of one series of fatty acids may, as a secondary effect, change serum concentrations in fatty acids of the other series as well, thus hampering the estimation of dietary intake (2). This
Figure 1. Scatter plots and regression lines of the proportion of saturated (SAFA), monounsaturated (MUFA) and polyunsaturated fatty acids (PUFA) in serum triglycerides vs. dietary intake of SAFA, MUFA and PUFA, respectively. The intake values are expressed as percentages of dietary fat. The data are from 5-year-old children whose 4-day food consumption was recorded just before the blood sampling ( $n=50$, Group I) and from other children whose food consumption was estimated 5 to 15 days before the blood sampling $(n=52)$, GROUP II).
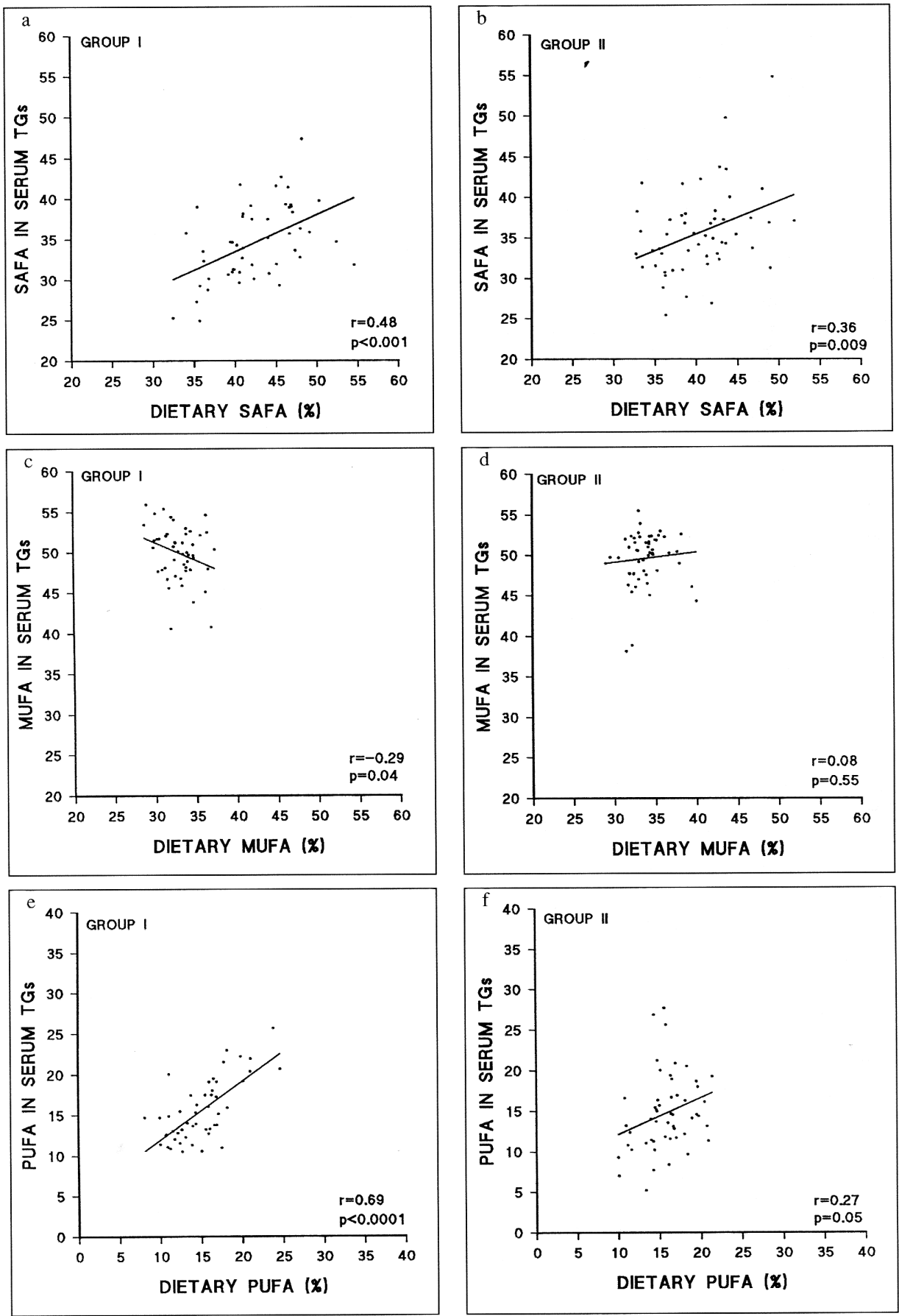

study clearly shows that the best serum lipid biomarkers of current fatty acid intake are total PUFAs and linoleic acid $(n-6)$ in serum triglycerides when the dietary data were collected just before the blood sampling. Previously, dietary linoleic acid intake and proportion of linoleic acid in serum triglycerides have correlated well in adults $(21,26)$, and in this study, the correlation was excellent also in children. The fact that linoleic acid is an essential fatty acid probably explains why the correlations between intake and proportions in the three serum lipid fractions are so good, and why the linoleic acid proportion of various tissues also closely reflects dietary intake (26).

Assuming that 4-day food records measure average intake of fatty acids accurately, our study suggests that fatty acids in serum triglycerides indicate reasonably well the quality of fat intake in children. However, a significant correlation was only obtained if dietary intake was 
assessed just before the blood sampling. Compared with the fatty acid composition of serum CE and PL, the overall fatty acid composition of serum TGs was closest to that of the subjects' diet. The advantage of measuring fatty acids in plasma lipids are that this method is not susceptible to errors in dietary reporting and it can thus be regarded as an objective qualitative estimate of dietary fat intake. However, the disadvantage of measurements from serum is that they do not provide information about the absolute intake of fatty acids. Clearly, serum triglyceride fatty acids are good biomarkers for shortterm intake of SAFAs and PUFAs, whereas MUFAs in all serum lipid fractions reflect MUFA intake poorly. Serum triglyceride fatty acid composition can be used when assessing short-term changes in children's fat intake both at group and individual level, for example in dietary intervention studies to monitor the success of intervention.

\section{Acknowledgement}

We wish to thank Mrs Soile Kotilainen, Dietary Technician, for the analysis of the food records, Ms. Marja-Leena Toukkari from the Joint Clinical Biochemistry Laboratory of the University of Turku for the fatty acid analyses, and Markku Vuorinen, MSc, for help in data handling and statistical analyses. This study was supported by grants from the Ministry of Social Affairs and Health, the Yrjö Jahnsson Foundation, the Finnish Cultural Fund, the Mannerheim League for Child Welfare, the Finnish Cardiac Research Foundation, the Foundation for Pediatric Research, Finland, the Academy of Finland, the Juho Vainio Foundation, the Signe and Ane Gyllenberg Foundation, the Turku University Foundation, Chymos Ltd, the Raisio Group, and Van den Bergh Foods Company.

\section{References}

1. Riboli E, Rönnholm H, Saracci R. Biological markers of diet. Cancer Surv 1987:6:685-718.

2. Hunter D. Biochemical indicators of dietary intake. In Willet W, ed. Nutritional Epidemiology. Monographs in epidemiology and biostatistics. Oxford, England: Oxford 'University Press, 1990; $15: 143-216$

3. Moilanen T, Räsänen L, Viikari J et al. Fatty acid composition in 3- to 18-year-old Finnish children and its relation to diet. Am J Clin Nutr 1985;42:708-13.

4. Glatz JF, Soffers AE, Katan MB. Fatty acid composition of serum cholesteryl esters and erythrocyte membranes as indicators of linoleic acid intake in man. Am J Clin Nutr 1989; 49:26976.

5. $\mathrm{v}$ Houweling AC, Kester AD, Kromhout D, Hornstra G. Comparison between habitual intake of polyunsaturated fatty acids and their concentrations in serum lipid fractions. Eur J Clin Nutr 1989;43:11-20

6. Lopes SM, Trimbo SL, Mascioli EA, Blackburn GL. Human plasma fatty acid variations and how they related to dietary intake. Am J clin Nutr $1991 \cdot 53 \cdot 628-37$

7. Vessby B, Gustafsson IB, Boberg J, Karlström B, Lithell H, Werner I. Substituting polyunsaturated for saturated fat as a single change in a Swedish diet: effects on serum lipoprotein metabolism and glucose tolerance in patients with hyperlipoproteinaemia. Eur J Clin Invest 1980;10:193-202.

8. Holman RT, Smythe L, Johnson S. Effect of sex and age on fatty acid composition of human serum lipids. Am J Clin Nutr 1979;32:2390-9.
Figure 2. Scatter plots and regression lines of the proportion of polyunsaturated fatty acids (PUFA) in serum cholesterol esters vs. dietary intake of PUFA. The intake values are expressed as percentages of dietary fat. The data are from 5-year-old children whose 4-day food consumption was recorded just before the blood sampling $(n=50$, Group I) and from other children whose food consumption was estimated 5 to 15 days before the blood sampling ( $n=52$, Group II).
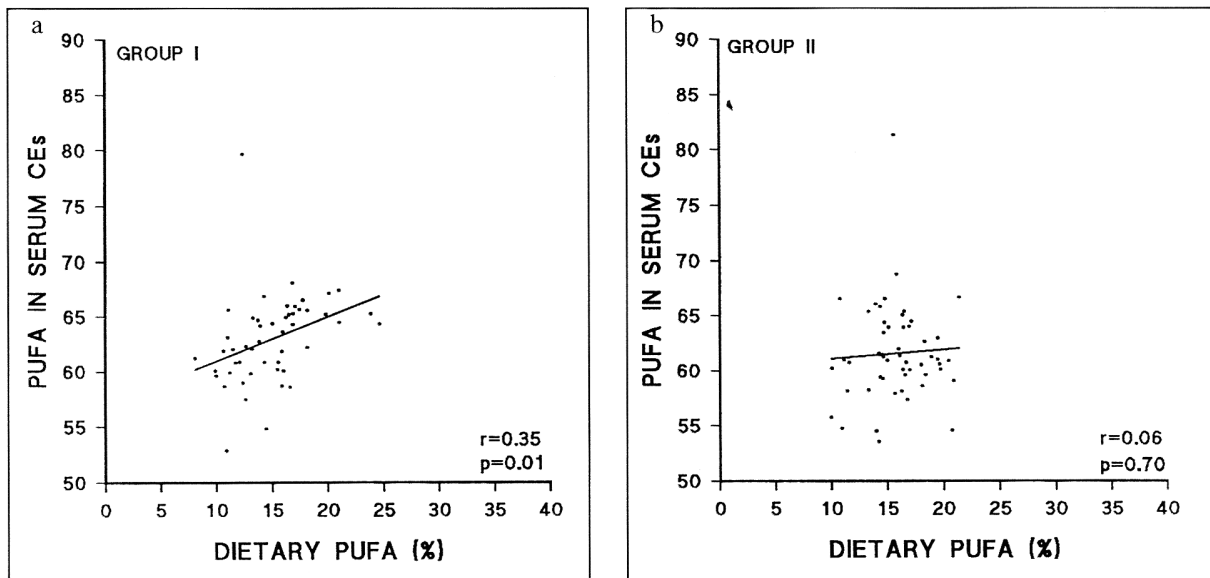

Figure 3. Scatter plots and regression lines of the proportion of polyunsaturated fatty acids (PUFA) in serum phospholipids vs. dietary intake of PUFA. The intake values are expressed as percentages of dietary fat. The data are from 5-year-old children whose 4-day food consumption was recorded just before the blood sampling ( $\mathrm{n}=\mathbf{5 0}$, Group $\mathrm{I}$ ) and from other children whose food consumption was estimated 5 to 15 days before the blood sampling ( $n=52$, Group II).
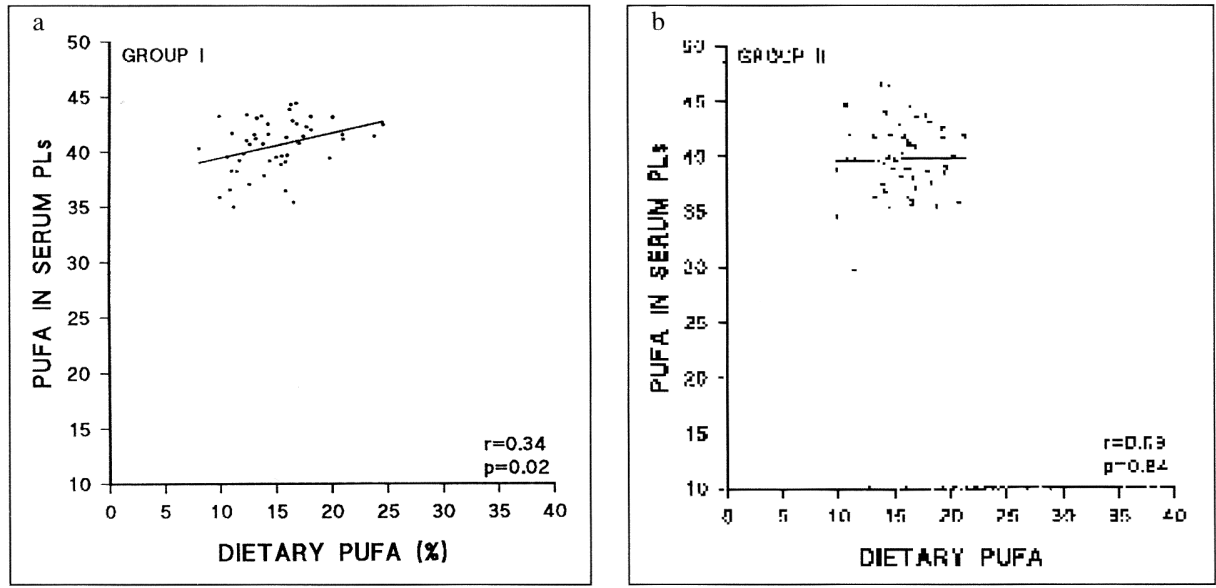

9. Knuiman JT, West CE, Hermus RJ, Hautvast JG. Fatty acid composition of cholesteryl esters in serum in boys from 16 developing and developed countries. Atherosclerosis 1980;37: 617-24.

10. Alling C, Westerberg B. Fatty acid composition of serum lecithin in healthy children. Eur J Pediatr 1981;137:197-201.

11. Rogiers V. Long chain nonesterified fatty acid patterns in plasma of healthy children and young adults in relation to age and sex. J Lipid Res 1981;22:1-6.

12. Moilanen T, Nikkari T, Räsänen L et al. Plasma cholesteryl ester fatty acids in 3- and 12-year-old Finnish children. Atherosclerosis 1983; 48:49-56.

13. Nikkari T, Räsänen L, Viikari J et al. Serum fatty acids in 8-year-old Finnish boys: correlation with qualitative dietary data and other serum lipids. Am J Clin Nutr 1983:37:848-54.

14. Koletzko B, Abiodun PO, Laryea MD, Schmid S, Bremer HJ. Comparison of fatty acid composition of plasma lipid fractions in well-nourished Nigerian and German infants and toddlers. J Pediatr Gastroenterol Nutr 1986; 5:581-5.

15. Decsi T, Koletzko B. Fatty acid composition of plasma lipid classes in healthy subjects from birth to young adulthood. Eur J Paediatr 1994; 153:520-5.

16. Moilanen T, Räsänen L, Viikari J, Åkerblom HK Nikkari T. Correlation of serum fatty acid composition with dietary data in children and young adults. Ann Med 1992; 24:67-70.

17. Lapinleimu H, Viikari J, Jokinen E et al. Prospective randomized trial in 1062 infants of diet low in saturated fat and cholesterol. Lancet
1995;345:471-6.

18. Niinikoski H, Viikari J, Rönnemaa T et al. A prospective randomized trial of low-saturated-fat, low-cholesterol diet during the first three years of life. The STRIP baby-project. Circulation 1996;94:1386-93.

19. Lands WE. Long-term fat intake and biomarkers. Am J Clin Nutr 1995;61(suppl): 721S-5S

20. Kohlmeier L. Future of dietary exposure assessment. Am J Clin Nutr 1995;61(suppl): 702S-9S.

21. Nikkari T, Luukainen P, Pietinen P, Puska P. Fatty acid composition of serum lipid fractions in relation to gender and quality of dietary fat. Ann Med 1995;27:491-8.

22. van't Veer P. Measuring nutritional exposures including biomarkers. Proc Nutr Soc 1994;53: 27 35 .

23. Siguel EN, Maclure M. Relative activity of unsaturated fatty acid metabolic pathways in humans. Metabolism 1987;36:664-9.

24. Brenner R. Factors influencing fatty acid chain elongation and desaturation. In: Vergoesen AJ, Crawford $\mathrm{M}$, editors. The role of fats in human nutrition. 2nd ed. London: Academic Press Ltd 1989:45-79.

25. Innis SM. Essential fatty acids in growth and development. Prog Lipid Res 1991;30:39-103.

26. James MJ, Gibson R, D’Angelo M Neumann M, Cleland L. Simple relationship exist between dietary linoleate and the $n-6$ fatty acids of human neutrophils and plasma. Am J Clin Nutr 1993;58:497-500 